Article

\title{
A Comparative Study on a Hydraulic and Water-Quality Analysis Method for Determining Rechlorination Injection Points for a Water-Supply Network
}

\author{
Sang Myoung Lee ${ }^{1}$, Ho Min Lee ${ }^{2}$, Do Guen Yoo $^{3}$ and Joong Hoon Kim ${ }^{1, *}$ \\ 1 School of Civil, Environmental and Architectural Engineering, Korea University, Seoul 02841, Korea; \\ waterman@korea.ac.kr \\ 2 Research Center for Disaster Prevention Science and Technology, Korea University, Seoul 02841, Korea; \\ dlgh86@korea.ac.kr \\ 3 Department of Civil Engineering, The University of Suwon, Gyeonggi-do 18323, Korea; \\ godqhr425@naver.com \\ * Correspondence: jaykim@korea.ac.kr; Tel.: +82-2-3290-3316
}

Received: 22 February 2019; Accepted: 2 April 2019; Published: 4 April 2019

check for updates

\begin{abstract}
Water supply facilities are vulnerable to extreme weather events, such as droughts and floods. To establish a sustainable solution that resists accidents and disasters, a distributed system is required. To supply high-quality tap water using the existing water-supply network, rechlorination facilities must be installed to secure residual chlorine at the pipe end. In this study, a process is developed to determine the injection points and dosages of rechlorination using the latest pressure-driven analysis. The method was compared to the results of demand driven analysis methods. The proposed model was applied to P City in Korea to draw results. A detailed evaluation was performed to study how water pressure head and demand-based hydraulic and water quality analysis results impact the injection points and dosages of rechlorination. Thus, the existing demand-based model shows significant spatial deviations in the pressure head in the presence of water pressure drops, which subsequently lead to over-estimation of chlorine injection dosages for maintaining the concentration of residual chlorine. However, the proposed model involves a numerically validated theory and draws more reasonable results for hydraulic, water quality, and rechlorination dosages. The proposed model can be used as a decision-making tool based on hydraulic analysis for the supply of water of a stable quality.
\end{abstract}

Keywords: water supply network; hydraulic analysis; water quality analysis; pressure-driven analysis; rechlorination facility; residual chlorine

\section{Introduction}

Global climate change has resulted in frequent floods and extreme droughts, and accelerates urbanization. Additionally, aging infrastructure has led to a higher probability of man-made accidents. In this context, the maintenance of a city's sustainability functions against natural and man-made disasters is an important issue. Water-supply networks (WSN) provide the infrastructure that supplies consumers with treated potable water, which must be provided with the correct volume, pressure, and quality. Thus, any occurrence of poor water quality directly impacts human life. A variety of water-quality issues in pipelines can thus arise. Direct damage to pipelines caused by man-made accidents, terrorist attacks, earthquakes, etc. can cause quality issues. Additionally, there can be shortages of raw water because of drought and residual chlorine concentrations (i.e., disinfection). 
This is related to abnormally high raw-water temperatures. In this aspect, maintaining an adequate residual chlorine concentration in a pipeline system is essential for secondary contamination control to inhibit microbial regrowth. Generally, highly concentrated residual chlorine occurs in the vicinity of water purification plants, where chlorine disinfection takes place. This is because of the pipeline system of a branched network and the characteristics of volatile chlorine disinfectant. Conversely, the chlorine level decreases at pipe ends. One of the methods to address this issue is to convert a branched network to a looped network or to install a rechlorination facility in the system.

In the former case, the scale of pipeline infrastructure that would require installation to achieve equalization effects is massive and would incur extreme costs. The latter case of installing a rechlorination facility incurs lower costs and is therefore widely used in the field (K-water [1]). Studies on the installation and operation of rechlorination facilities originally focused on minimizing the disinfectant mass at chlorine-injection facilities. Boccelli et al. [2] conducted a water-quality analysis in pipelines using the primary decay reaction of chlorine, aiming to minimize the disinfectant mass for predetermined rechlorination injection points. As a result, an adequate water quality was achieved with less disinfectant mass, compared to the existing method of injecting disinfectants only into water sources.

Munavalli and Mohan Kumar [3], Tryby et al. [4], and Propato and Uber [5] proposed a design and operational method to maximize the effects of rechlorination using a single-purpose optimization method. Munavalli and Mohan Kumar [3] used a genetic algorithm as an optimization method and set the minimization of the residual chlorine concentration as an objective function to determine the injection concentration at predetermined injection points. Tryby et al. [4] attempted to minimize the disinfectant mass for injection and applied mixed-integer linear programming to determine the rechlorination injection points. Propato and Uber [5] achieved optimization by setting an objective function as the minimal total of the squared deviations of residual concentrations to assess the effects of rechlorination, focusing on equalization. More recently, Yoo et al. [6] used a harmony search algorithm, a meta-heuristic optimization method, to study issues requiring the installation of a rechlorination facility to determine the rechlorination points for minimizing the disinfectant mass.

Prasad et al. [7], Ostfeld and Salomons [8], Islam et al. [9], Choi et al. [10], and other research teams evaluated residual chlorine by addressing not only residual chlorine concentrations, but also the hydraulic performance of the water-supply system or additional water-quality assessment factors. Prasad et al. [7] proposed a multi-purpose optimization method that minimized the total chlorine mass for injection (i.e., water-quality indicator) and simultaneously maximized the water-supply mass (i.e., hydraulic indicator) in an attempt to determine the location and operational methods (i.e., scheduling) of a rechlorination facility. Ostfeld and Salomons [8] optimized the operational method (i.e., hydraulic indicator) of pumps and the operational method (i.e., water quality indicator) of a rechlorination facility while minimizing the operational and construction costs of a water supply. Islam et al. [9] proposed a water-quality index (WQI) to provide a single value to reflect microbial, chemical, and aesthetic water quality standards. Using the WQI value as a basis, another study was conducted to determine an optimal rechlorination mass for injection points. Choi et al. [10] analyzed the effects of residual chlorine in relation to rechlorination for water-quality improvement in the supply process. They set three assessment indices of decreasing residual chlorine concentrations between a water purification plant and pipe ends. They also addressed the decrease in total chlorine mass for injection and the decrease in disinfection by-product generation.

When looking at past studies on rechlorination, most methodologies obtained residual chlorine concentration results through hydraulic and water-quality analyses and determined an optimal design or operational method based on the results. Most extant studies, however, were conducted using EPANET2 (Rossman [11]), a legacy model for a demand-driven analysis (DDA). With DDA, workers perform hydraulic analysis under the premise that a given water volume is supplied under all circumstances, and all water volumes supplied to the network are considered as known values. Therefore, it cannot directly simulate unplanned events, such as water-supply decreases caused by 
water pressure losses. This has generated distorted hydraulic statistics for water-quality analysis results. One method used to address this issue is a pressure-driven analysis (PDA). PDA provides a supply amount (i.e., total of the consumption amount and leak amount) as an unknown value, affected by residual heads and water pressures. When looking at a PDA from a hydraulic perspective in the water-supply pipeline system, studies have been conducted by Giustolisi et al. [12,13], Wu et al. [14], Lee et al. [15], Yoo et al. [16], etc. These studies suggested that DDA could not precisely mathematically simulate the event of pressure decreases and that the PDA could give more realistic results. From a water-quality analysis perspective, Seyoum and Tanyimboh [17] and Seyoum et al. [18-20] conducted studies on how a PDA could affect water-quality analysis. These studies showed that, for DDA, the assumption of supplying all demands, despite actual water-pressure decreases, could lead to an underestimation of water age. Thus, it was suggested that a decrease in the flow rate in the pipe caused by a pressure decrease could lead to relative increases in water age from a PDA perspective. However, these studies only suggested the general tendency of hydraulic and water-quality analysis from a PDA, implying that residual chlorine concentration levels could change according to actual flow rates in the pipes. Thus, there has yet to be any analysis on how hydraulic and water-quality analysis results impact the final chlorine injection amount and the selection of rechlorination injection points. Furthermore, a pressure-driven hydraulic analysis has been pre-installed in several commercial programs (WaterGEMs, Bentley [21]) and source codes (EPANET3 [22]). However, the development of a model for repeatedly conducting water-quality analysis and evaluating its result based on a pressure-driven hydraulic analysis has not been proposed.

An analysis of water quality changes in WSN is a direct extension of a hydraulic WSN analysis and can be used effectively. That is, a water-quality analysis involves a process of calculating chemical combinations, concentration changes, water ages, etc., in WSN, based on the results of hydraulic analysis. The flow direction, which indicates the flow rate in pipelines and flow routes of water within pipelines, is used to determine the combination and water age and other hydraulic characteristics that affect the transfer of pollution sources and concentration decrease. Most hydraulic models use one-dimensional flows and reaction transfers, which express the concentration in a particular pipe as a function of the distance and time to predict concentration changes in ingredients caused by transfers within WSN and calculate the formation of reactants and concentration decreases. A typical example of volume and wall reactions is the disinfection reaction, which is most commonly used in hydraulic analyses. When water leaves a reservoir and flows through pipelines, it generates various chemical reactions with the disinfectant. Chlorine reacts to natural organic matters within the volume, to the bio-membranes within the pipe walls, and to the pipe material, causing decay. Generally, chlorine decay models are classified into a first-order decay and power-law decay (nth order) of second or higher order, according to the form of the attenuation equation (Carrico and Singer [23]; Yoo et al. [6]). The primary chlorine attenuation model for the volume and wall reaction is commonly used in studies for its simplicity and availability (Courtis et al. [24]; Powell et al. [25]; Tamminen and Ramos [26]). Therefore, the first-order chlorine decay model, which accounts for bulk and wall effects, is used in this study.

In this paper, a model is developed for determining rechlorination injection points to maintain an adequate residual chlorine concentration level in the system using a PDA, including a water-quality analysis. Furthermore, results of the existing DDA on rechlorination injection points and dosages are obtained and compared with that of the PDA results. Lastly, the proposed model is applied to an actual WSN under normal and abnormal conditions, and a detailed evaluation is performed to study how hydraulic and water-quality analysis results affect the determination of rechlorination injection points.

\section{Materials and Methods}

\subsection{Definition of Abnormal Condition in WSN}

Abnormal situations that can occur in a water supply network system are very diverse. For instance, abnormal situations include pipeline breaks, shutdown of the pump, and reduction of the water level 
(reservoir, reservoir) due to drought from the hydraulic point of view. In addition, the exceptional variation of the effluent chlorine concentration at the water treatment plant can be considered as an abnormal condition of the water quality factor. The chlorine concentration is affected by the hydraulic factors (pipe flow, nodal water pressure head, etc.) in a water supply network. However, in the case of DDA, the hydraulic factors are calculated assuming that all the demands of the nodal point are satisfied regardless of the nodal water pressure head, so that the validity of the hydraulic analysis results cannot be secured in the event of abnormal conditions. Therefore, the reliability of the water quality analysis results also cannot be guaranteed. Therefore, in this study, we presented the results of an abnormal situation scenario when the water level of the reservoir decreases, in order to compare the DDA and the PDA.

\subsection{K-NriskQ}

K-NRisk (K-water [27]) is a pressure-driven demand simulation model that analyzes areas with water-supply suspensions and water-pressure shortages under abnormal conditions to quantify supply availability for demand. It typically performs the function of pressure-driven leak simulation for a precise hydraulic analysis simulation, according to changes in the leak amount. Its major difference from EPANET3, which recently became open source, is that it automatically performs a sensitivity analysis of input factors used for a PDA. It quantifies the uncertainty innate in simulation models and provides a function for novice users to easily operate typical analysis scenarios of abnormal situations. In particular, it aims to develop a user-friendly decision-making tool for analysis efficiency improvement, such as for local water-supply system operation efficiency boost projects and water-flow rate improvement projects, which require a WSN hydraulic analysis.

K-NRiskQ (K-water [28]) is an advanced model that focuses on the water-quality analysis function of K-NRisk. It was developed based on a parameter sensitivity analysis function and a simulation function for residual chlorine equalization. Parameter sensitivity analysis was designed to intuitively understand the changes in network water quality according to changes in the pipe wall and body coefficients and to simulate water-quality changes in relation to changes (e.g., minimum, average, maximum temperature) set in accordance with the water temperature of body coefficients in a bottle test. Residual chlorine equalization simulations were designed to provide an automatic comparative review of rechlorination injection, manually performed, to determine rechlorination injection points for boosting water-quality satisfaction. Our study is based on the residual chlorine equalization simulation function designed in K-NRiskQ. Table 1 shows the available functions of the major hydraulic and water-quality analysis models for WSN. It suggests that the water-quality analysis function, via PDA, is more valid in K-NRiskQ than other tools.

Table 1. Function comparison between major hydraulic/water-quality analysis models.

\begin{tabular}{|c|c|c|c|c|}
\hline Function & EPANET2 & EPANET3 & K-NRisk & K-NRiskQ \\
\hline $\begin{array}{l}\text { Pressure driven analysis (head } \\
\text { outflow relationship) }\end{array}$ & $X^{*}$ & $\mathrm{O}^{*}$ & $\mathrm{O}$ & $\mathrm{O}$ \\
\hline $\begin{array}{l}\text { Quantification through leakage } \\
\text { performance index }\end{array}$ & $x$ & $x$ & $\mathrm{O}$ & $\mathrm{O}$ \\
\hline $\begin{array}{l}\text { Scenarios for multiple abnormal } \\
\text { situations created }\end{array}$ & $x$ & $x$ & $\mathrm{O}$ & $\mathrm{O}$ \\
\hline $\begin{array}{l}\text { Sensitivity analysis of main factors in } \\
\text { hydraulic/water quality analysis }\end{array}$ & $x$ & $x$ & $\begin{array}{c}\Delta^{*} \text { (hydraulic } \\
\text { analysis })\end{array}$ & $\mathrm{O}$ \\
\hline $\begin{array}{l}\text { Analysis of representative tasks (e.g., } \\
\text { iterative water quality simulation) in } \\
\text { hydraulic/water quality analysis }\end{array}$ & $x$ & $x$ & $\begin{array}{l}\Delta \text { (hydraulic } \\
\text { analysis) }\end{array}$ & $\mathrm{O}$ \\
\hline Residual chlorine equalization & $x$ & $x$ & $x$ & $\mathrm{O}$ \\
\hline
\end{tabular}




\subsection{Methodology for Determining Rechlorination Points}

\subsubsection{Objective Function and Constraints}

The objective function used in this model is as shown in Equation (1). It aims to minimize the total disinfectant mass additionally injected. The determinant variables of the model are the locations of the rechlorination points, the disinfectant concentration, and the mass injected into each rechlorination point:

$$
\text { minimize } f=\sum_{i=1}^{n n} M i
$$

where $f$ indicates the total disinfectant mass $(\mathrm{kg} / \mathrm{d}), M i$ is the disinfectant mass at joint $i(\mathrm{~kg} / \mathrm{d})$, and $n n$ is the total number of joints. The constraints in this model can be mainly classified into two categories. The first is the residual chlorine concentration at each joint. As shown in Equation (2), the concentration at all joints must be between the proposed minimum and maximum values:

$$
C l_{\min } \leq C l_{i} \leq C l_{\max }(i=1, \ldots, n n)
$$

where $C l_{i}$ indicates the residual chlorine concentration at joint $i(\mathrm{mg} / \mathrm{L})$, and $C l_{\text {min }}$ and $C l_{\text {max }}$ are the minimum and maximum residual chlorine concentrations allowed, respectively $(\mathrm{mg} / \mathrm{L})$. The second category is the number of rechlorination facilities to be installed. The number of facilities to be installed is predetermined and set as constraints for this model. Therefore, this model supports different numbers of facilities in scenarios:

$$
N=\{1, \ldots, n n\}
$$

where $N$ denotes the number of possible designed boosters.

\subsubsection{Methodology Procedure}

In this study, two scenarios of normal and abnormal conditions were set and analyzed to study residual chlorine. A greedy algorithm was applied to explore rechlorination injection points. A greedy algorithm is one of the simplest methods of making the best optimal choice at an early stage. Whereas it does not always guarantee an optimal result, it has the advantage of promptly obtaining a value close to an optimal solution. Scenarios are selected from either a normal or an abnormal situation. Figure 1 shows the progress diagram of this study. The purpose of the greedy algorithm is to keep the residual chlorine standard above the minimum and below the maximum for all target joints. When the standard deviates from this acceptable range, it is configured to first select ones with the least error.

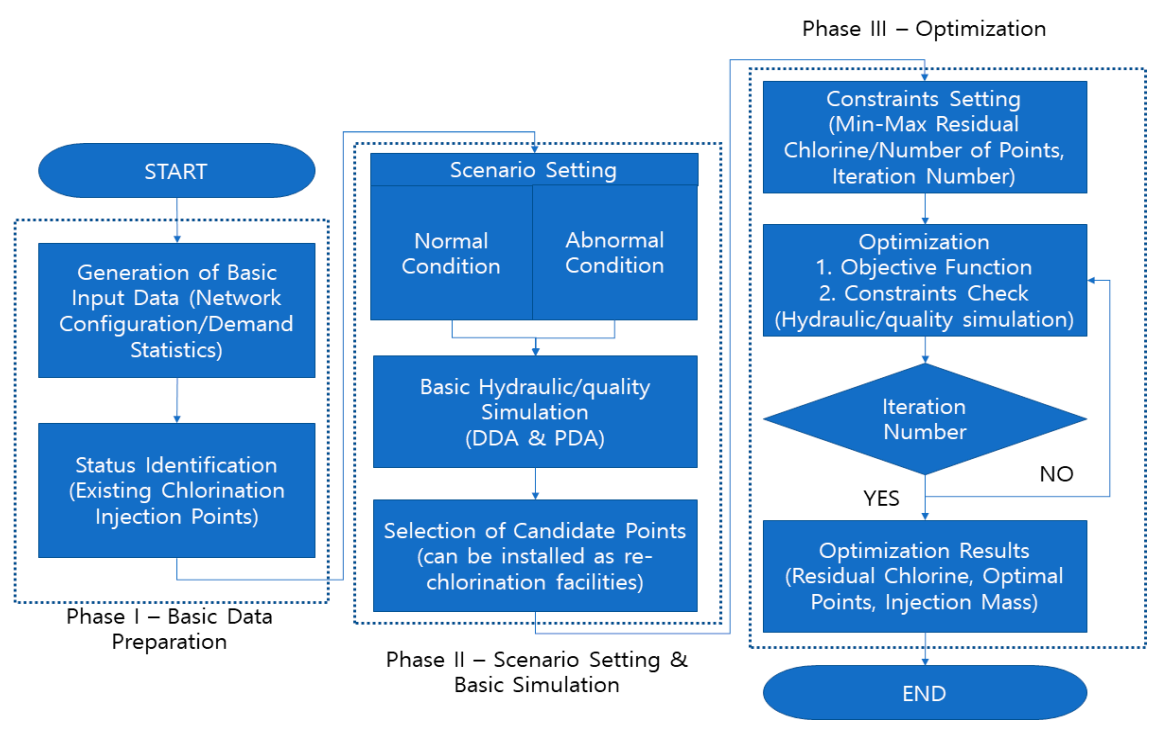

Figure 1. Proposed model operation procedure. 
The procedure for determining rechlorination injection points is as follows:

(1). Check the break points and water sources of the target SWN where chlorine injection points are set.

(2). Distinguish between normal and abnormal scenarios, and detail the scenario.

(3). Check the hydraulic and water-quality analysis results from the current chlorine injection for normal and abnormal scenarios via PDA and DDA analyses.

(4). Set a candidate group for chlorine injection. The break points in the target area in Figure 2 were set as the candidate group for chlorine injection for this study. However, this was set as configurable by a model user.

(5). Set quality constraints and the number of rechlorination injection points to determine the optimal conditions for residual chlorine equalization. Set the maximum and minimum values and the number of rechlorination injection points, which are the acceptable range for residual chlorine concentration.

(6). Perform a greedy algorithm to satisfy the concentration conditions for residual chlorine set by a user and calculate the number of chlorine injection points within the acceptable range of the residual chlorine concentration and dosage. To confirm the constraints, a hydraulic analysis is required by trial calculation. After the calculation is complete, propose the rechlorination injection method as a result.

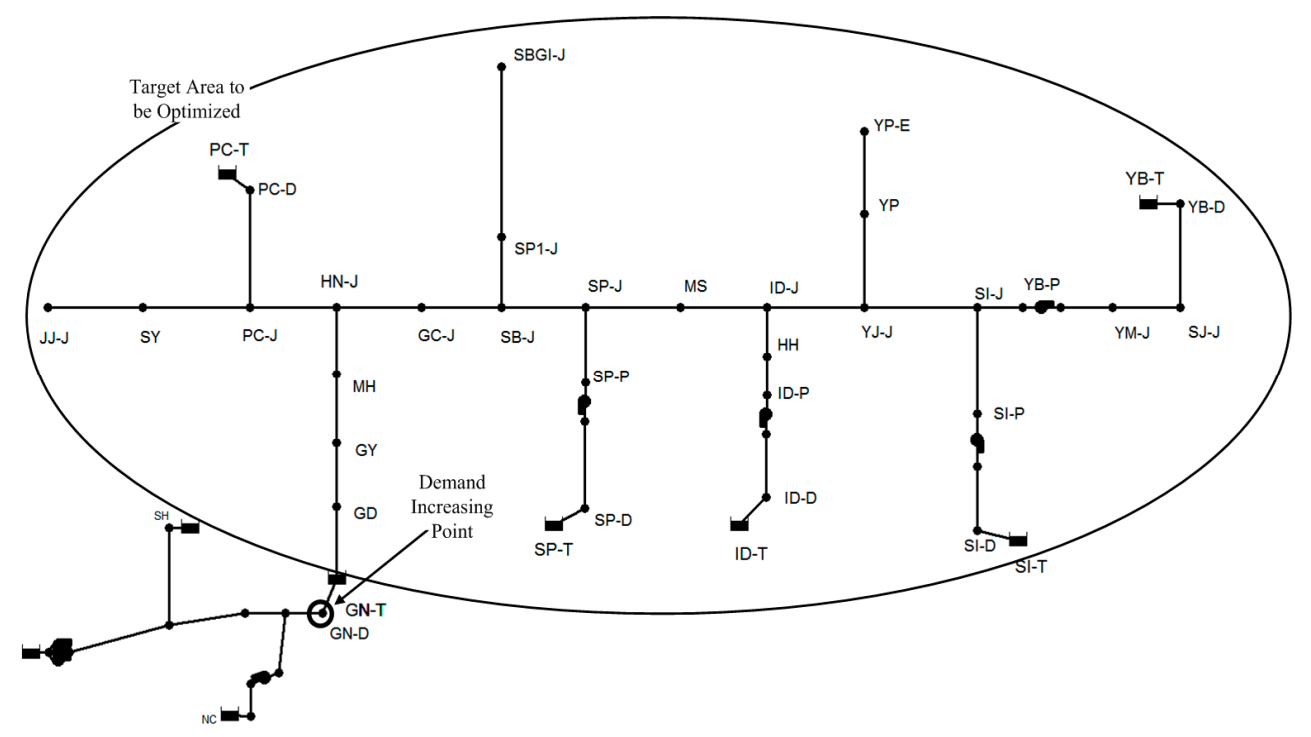

Figure 2. Target WSN (P City, Republic of Korea) (Yoo et al. [6]).

\section{Application and Result}

\subsection{Subject WSN}

The region used as a case study was the WSN of P City in Korea, which was first studied by Yoo et al. [6]. P City is a small-to-medium-sized city $\left(826 \mathrm{~km}^{2}\right)$ that supplies water to 119,750 residents. Its water-supply system comprises approximately $85-\mathrm{km}$-long water transmission pipes and 773-km-long water distribution pipes. Eight water distribution locations are used to supply $54,020-\mathrm{m}^{3}$-per-day of water. Figure 2 shows the structure of the water transmission pipes of the water supply system in P City. P City is expected to have additional demand for 10,000 CMD of water at point GN-D (the circled area in Figure 2), owing to changes in water sources and additional urban development. According to the current Korean standards, the water quality of residual chlorine must range between $0.1 \mathrm{mg} / \mathrm{L}$ and $4.0 \mathrm{mg} / \mathrm{L}$ (KWWA [29]). Moreover, it is regulated to be $0.4 \mathrm{mg} / \mathrm{L}$ or higher when polluted by, or when it has the potential to be polluted by, pathogenic microbes. Therefore, 
a WSN operator in P City strives to maintain water quality from $0.4 \mathrm{mg} / \mathrm{L}$ to $4.0 \mathrm{mg} / \mathrm{L}$, even when additional water is needed, by installing rechlorination injection facilities downstream of point GN-D.

The result of the maintenance and water-quality review for maintaining the current chlorine injection points and dosage, according to the additional water supply demand, is shown in Table 2.

Table 2. DDA and PDA hydraulic/water quality analysis results, considering additional demand for water.

\begin{tabular}{|c|c|c|c|c|c|c|}
\hline \multicolumn{4}{|c|}{ EPANET2 DDA } & \multicolumn{3}{|c|}{ K-NRiskQ PDA } \\
\hline Junction ID & $\begin{array}{l}\text { Pressure } \\
\text { Head (m) }\end{array}$ & $\begin{array}{l}\text { Available } \\
\text { Demand } \\
\text { (CMD) }\end{array}$ & $\begin{array}{c}\text { Residual } \\
\text { Chlorine } \\
\text { (mg/L) }\end{array}$ & $\begin{array}{l}\text { Pressure } \\
\text { Head (m) }\end{array}$ & $\begin{array}{l}\text { Available } \\
\text { Demand } \\
\text { (CMD) }\end{array}$ & $\begin{array}{c}\text { Residual } \\
\text { Chlorine } \\
\text { (mg/L) }\end{array}$ \\
\hline GN-D & 28.33 & $21,723.00$ & 0.45 & 31.05 & $21,723.00$ & 0.73 \\
\hline GD & 5.90 & 0.00 & 0.58 & 5.93 & 0.00 & 0.58 \\
\hline GY & 40.79 & 0.00 & 0.54 & 40.88 & 0.00 & 0.56 \\
\hline MH & 32.19 & 0.00 & 0.52 & 32.29 & 0.00 & 0.55 \\
\hline HN-J & 59.01 & 0.00 & 0.49 & 59.14 & 0.00 & 0.53 \\
\hline PC-J & 52.64 & 0.00 & 0.47 & 52.77 & 0.00 & 0.53 \\
\hline SY & 57.34 & 0.00 & 0.45 & 57.47 & 0.00 & 0.51 \\
\hline JJ-J & 38.54 & 1000.00 & 0.22 & 38.67 & 1000.00 & 0.39 \\
\hline PC-D & 12.29 & 5846.00 & 0.44 & 12.53 & 5342.00 & 0.51 \\
\hline GC-J & 57.28 & 294.00 & 0.47 & 57.46 & 294.00 & 0.51 \\
\hline SB-J & 59.03 & 0.00 & 0.41 & 59.37 & 0.00 & 0.44 \\
\hline SP-J & 62.43 & 0.00 & 0.37 & 62.89 & 0.00 & 0.48 \\
\hline MS & 64.16 & 0.00 & 0.36 & 64.66 & 0.00 & 0.47 \\
\hline ID-J & 65.85 & 0.00 & 0.34 & 66.37 & 0.00 & 0.43 \\
\hline YJ-J & 59.51 & 0.00 & 0.29 & 60.12 & 0.00 & 0.43 \\
\hline SI-J & 68.00 & 0.00 & 0.25 & 68.88 & 0.00 & 0.40 \\
\hline YB-P & 50.05 & 0.00 & 0.22 & 51.01 & 0.00 & 0.40 \\
\hline YM-J & 27.38 & 0.00 & 0.17 & 30.19 & 0.00 & 0.36 \\
\hline SJ-J & 48.00 & 0.00 & 0.15 & 50.89 & 0.00 & 0.37 \\
\hline YB-D & 6.07 & 3426.00 & 0.14 & 9.26 & 2692.26 & 0.35 \\
\hline SP1-J & 60.98 & 0.00 & 0.25 & 61.32 & 0.00 & 0.45 \\
\hline SBGI-J & 36.31 & 116.00 & 0.01 & 36.65 & 116.00 & 0.06 \\
\hline SP-P & 52.75 & 0.00 & 0.30 & 53.21 & 0.00 & 0.45 \\
\hline SP-D & 59.60 & 835.00 & 0.25 & 60.06 & 835.00 & 0.43 \\
\hline ID-P & 13.49 & 0.00 & 0.22 & 14.01 & 0.00 & 0.42 \\
\hline ID-D & 36.36 & 2760.00 & 0.21 & 36.88 & 2760.00 & 0.38 \\
\hline $\mathrm{HH}$ & 38.98 & 0.00 & 0.26 & 39.50 & 0.00 & 0.43 \\
\hline YP & 75.39 & 0.00 & 0.10 & 76.01 & 0.00 & 0.39 \\
\hline YP-E & 83.70 & 200.00 & 0.05 & 84.32 & 200.00 & 0.39 \\
\hline SI-P & 22.46 & 0.00 & 0.22 & 24.48 & 0.00 & 0.40 \\
\hline SI-D & 10.96 & 5000.00 & 0.20 & 13.94 & 4820.85 & 0.39 \\
\hline Min. & 5.90 & & 0.01 & 5.93 & & 0.06 \\
\hline Max. & 83.70 & & 0.58 & 84.32 & & 0.73 \\
\hline Average & 44.70 & & 0.30 & 45.55 & & 0.44 \\
\hline SD & 21.10 & & 0.15 & 20.71 & & 0.11 \\
\hline
\end{tabular}


The result of a DDA simulation for additional water-supply demand showed that 21 break points did not satisfy the lower required limit of $0.4 \mathrm{mg} / \mathrm{L}$. In the case of YP-E and SBGI-J, both having long travel times, the expected values of chlorine concentration were $0.05 \mathrm{mg} / \mathrm{L}$ and $0.01 \mathrm{mg} / \mathrm{L}$, respectively. They did not meet the legal minimum standard as well. Additionally, the average residual chlorine concentration of major break points was also observed to be $0.30 \mathrm{mg} / \mathrm{L}$ below the minimum standard. Therefore, to supply safe tap water through pipe ends, it is necessary to install rechlorination facilities to secure residual chlorine.

According to the PDA simulation result, it was confirmed that nine break points did not meet the lower limit of $0.4 \mathrm{mg} / \mathrm{L}$ requested by the operator. The break point with the lowest expected value was SBGI-J with $0.06 \mathrm{mg} / \mathrm{L}$, which was below the legal minimum standard. The average residual chlorine concentration of breakpoints was $0.44 \mathrm{mg} / \mathrm{L}$, satisfying the minimum standard, differing from the DDA analysis result.

The DDA and PDA results of the residual chlorine analysis showed disparity, and the number of breakpoints satisfying the acceptable standard showed a difference, because, during calculation, it was assumed that all basic demands were met with the corresponding supply, despite the fact that the available amounts should decrease, owing to water-pressure decreases in real situations. Such an assumption results in increased deviation in the water pressure head and residual chlorine concentration between break points. Additionally, water-pressure head decreases lead to decreases in the available supply in a DDA. Regarding break point YB-D, the simulation showed that the available amount of supply was $2692 \mathrm{CMD}$, compared to the basic demand of $3426 \mathrm{CMD}$, indicating that approximately $79 \%$ of demand could be met. Such a decrease in the amount of water supply can cause a relative increase in the residual chlorine concentration.

\subsection{Setting Analysis Scenarios}

This study aims to identify rechlorination points that can address the current below-standard residual chlorine concentrations under normal conditions and to determine rechlorination injection points when the head of the water source (i.e., main source) is operated at a 5-m-lower point because of abnormal conditions. Unlike the study of Yoo et al. [6], our reason for additionally accounting for an abnormal situation is that many studies have raised an issue regarding the adequacy of the DDA results under abnormal conditions. Thus, because water-quality analysis results are used as basic input data, it is also necessary to conduct a water-quality analysis for abnormal conditions. In this study, the model was operated with 2,3, and 4 rechlorination injection points, and the results were compared and analyzed. A total of 40,000 repetitive trial calculations were conducted for each model.

The HOR used in the DDA for demand is an equation proposed by Wagner et al. [30]. The minimum water pressure for supplying break points was set to $0 \mathrm{~m}$, and the ideal water pressure for $100 \%$ supply-to-demand was set to $15 \mathrm{~m}$. Yoo et al. [6] suggested the bulk and wall decay coefficient of the P-city network based on a bottle test and the results of previous studies [31,32], separately. Reflecting on the results of the literature, the bulk and wall decay coefficients entered for modelling the residual chlorine concentration in pipes were set to $-0.5760 \mathrm{~d}-1$ and $-0.1 \mathrm{~d}-1$, respectively.

\subsection{Application and Results}

Table 3 shows the results of hydraulic and water quality analyses for abnormal conditions, assuming that the level of the water source decreased by $5 \mathrm{~m}$. The DDA simulation result under abnormal conditions showed similar trends to those of normal conditions. However, it was confirmed that the number of points below the residual chlorine standard significantly decreased from 9 to 3 , according to the PDA simulation result. This leads to a situation where the available amount of water supply in the system decreases as the amount of water source decreases, and the residual chlorine concentration in the system increases, as opposed to normal conditions.

Finally, when looking at the hydraulic and water-quality analysis results for both normal and abnormal conditions prior to additional rechlorination, it is shown that the change in water quality 
is insignificant, despite the decrease in the number of heads of water sources, because the available amount of supply is the same in the DDA. However, it was shown that the change in the available amount of supply greatly affected the water-quality analysis result in the case of PDA. Eventually, from a rechlorination injection perspective, it can be expected that the number of total rechlorination injections will decrease during abnormal conditions. The rechlorination injection points may appear different according to the system status, deviations by break points, etc.

Table 3. Hydraulic and water quality results under abnormal conditions.

\begin{tabular}{|c|c|c|c|c|c|c|}
\hline \multicolumn{4}{|c|}{ EPANET2 DDA } & \multicolumn{3}{|c|}{ K-NRiskQ PDA } \\
\hline Junction ID & $\begin{array}{l}\text { Pressure } \\
\text { Head (m) }\end{array}$ & $\begin{array}{l}\text { Available } \\
\text { Demand } \\
\text { (CMD) }\end{array}$ & $\begin{array}{c}\text { Residual } \\
\text { Chlorine } \\
\text { (mg/L) }\end{array}$ & $\begin{array}{l}\text { Pressure } \\
\text { Head (m) }\end{array}$ & $\begin{array}{l}\text { Available } \\
\text { Demand } \\
\text { (CMD) }\end{array}$ & $\begin{array}{c}\text { Residual } \\
\text { Chlorine } \\
\text { (mg/L) }\end{array}$ \\
\hline GN-D & 28.33 & $21,723.00$ & 0.45 & 31.05 & $21,723.00$ & 0.73 \\
\hline GD & 0.90 & 0.00 & 0.58 & 0.96 & 0.00 & 0.58 \\
\hline GY & 35.79 & 0.00 & 0.54 & 35.99 & 0.00 & 0.55 \\
\hline $\mathrm{MH}$ & 27.19 & 0.00 & 0.52 & 27.42 & 0.00 & 0.55 \\
\hline HN-J & 54.01 & 0.00 & 0.49 & 54.29 & 0.00 & 0.53 \\
\hline PC-J & 47.64 & 0.00 & 0.47 & 47.93 & 0.00 & 0.52 \\
\hline SY & 52.34 & 0.00 & 0.45 & 52.63 & 0.00 & 0.50 \\
\hline JJ-J & 33.54 & 1000.00 & 0.22 & 33.83 & 1000.00 & 0.37 \\
\hline PC-D & 7.29 & 5846.00 & 0.44 & 7.89 & 4240.62 & 0.49 \\
\hline GC-J & 52.28 & 294.00 & 0.47 & 52.64 & 294.00 & 0.51 \\
\hline SB-J & 54.03 & 0.00 & 0.41 & 54.68 & 0.00 & 0.44 \\
\hline SP-J & 57.43 & 0.00 & 0.37 & 58.29 & 0.00 & 0.49 \\
\hline MS & 59.16 & 0.00 & 0.36 & 60.09 & 0.00 & 0.45 \\
\hline ID-J & 60.85 & 0.00 & 0.34 & 61.82 & 0.00 & 0.42 \\
\hline YJ-J & 54.51 & 0.00 & 0.29 & 55.65 & 0.00 & 0.43 \\
\hline SI-J & 63.00 & 0.00 & 0.25 & 64.59 & 0.00 & 0.45 \\
\hline YB-P & 45.05 & 0.00 & 0.22 & 46.77 & 0.00 & 0.43 \\
\hline YM-J & 22.38 & 0.00 & 0.17 & 26.94 & 0.00 & 0.39 \\
\hline SJ-J & 43.00 & 0.00 & 0.15 & 47.69 & 0.00 & 0.41 \\
\hline YB-D & 1.07 & 3426.00 & 0.14 & 6.22 & 2206.12 & 0.40 \\
\hline SP1-J & 55.98 & 0.00 & 0.25 & 56.63 & 0.00 & 0.44 \\
\hline SBGI-J & 31.31 & 116.00 & 0.01 & 31.97 & 116.00 & 0.01 \\
\hline SP-P & 47.75 & 0.00 & 0.30 & 48.62 & 0.00 & 0.48 \\
\hline SP-D & 54.60 & 835.00 & 0.25 & 55.47 & 835.00 & 0.43 \\
\hline ID-P & 8.49 & 0.00 & 0.22 & 9.46 & 0.00 & 0.41 \\
\hline ID-D & 31.36 & 2760.00 & 0.21 & 32.33 & 2760.00 & 0.41 \\
\hline $\mathrm{HH}$ & 33.98 & 0.00 & 0.26 & 34.95 & 0.00 & 0.41 \\
\hline YP & 70.39 & 0.00 & 0.10 & 71.53 & 0.00 & 0.41 \\
\hline YP-E & 78.70 & 200.00 & 0.05 & 79.84 & 200.00 & 0.37 \\
\hline SI-P & 17.46 & 0.00 & 0.22 & 21.74 & 0.00 & 0.40 \\
\hline SI-D & 5.96 & 5000.00 & 0.20 & 12.52 & 4567.84 & 0.42 \\
\hline Min. & 0.90 & & 0.01 & 0.96 & & 0.01 \\
\hline Max. & 78.70 & & 0.58 & 79.84 & & 0.73 \\
\hline Average & 39.86 & & 0.30 & 41.37 & & 0.45 \\
\hline SD & 20.99 & & 0.15 & 20.34 & & 0.11 \\
\hline
\end{tabular}


Figure 3 diagrams an optimal model operation under normal and abnormal conditions where there is a need to install 2, 3, or 4 rechlorination injection facilities in the system. It shows the total rechlorination injection dosage, which is the objective function of the optimization methodology. When applying the PDA under normal conditions, the result shows that some rechlorination dosage increases for determining two points. However, it shows a decreasing tendency in the total injection dosage required, because the number of installation points increases under both normal and abnormal conditions and for both DDA and PDA analyses. Because the greedy algorithm does not guarantee an optimal solution for all issues, the optimization performance of the proposed methodology in this study was evaluated and compared to the result from the methodology proposed by Yoo et al. [6]. Figure 4 shows the result of the DDA under normal conditions using the harmony search (HS), a metaheuristic optimization methodology. Figures $3 \mathrm{a}$ and 4 provide the results of the greedy algorithm and HS for the same scenario and the hydraulic analysis method. When comparing the results, the HS result is observed to be superior (lesser injection amount) in terms of the final total injection amount. However, the greedy algorithm also showed an objective function result at almost the same level. The purpose of this study is to compare the result of applying DDA and PDA and normal and abnormal conditions in determining the rechlorination injection amount, rather than to obtain the results of better injection amounts. Therefore, whereas the greedy algorithm does not show superior results compared to the HS optimization method, it was confirmed that it can provide a close-to-optimal result.

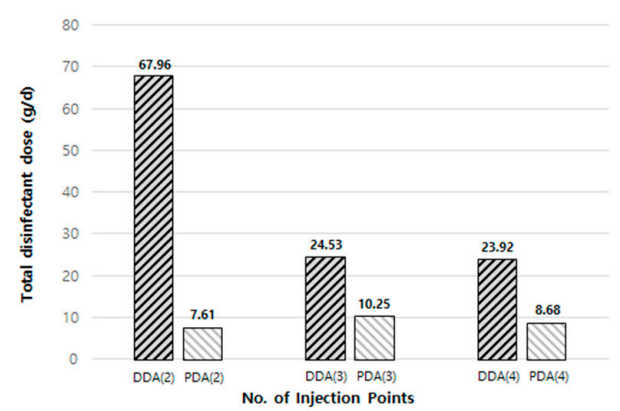

(a) Normal condition

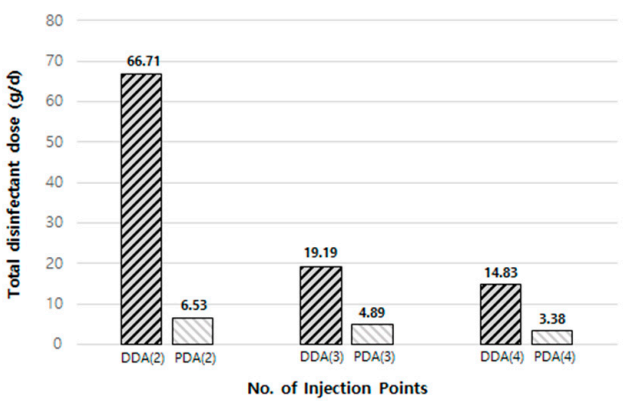

(b) Abnormal condition

Figure 3. Changes in optimal injection amount by scenario.

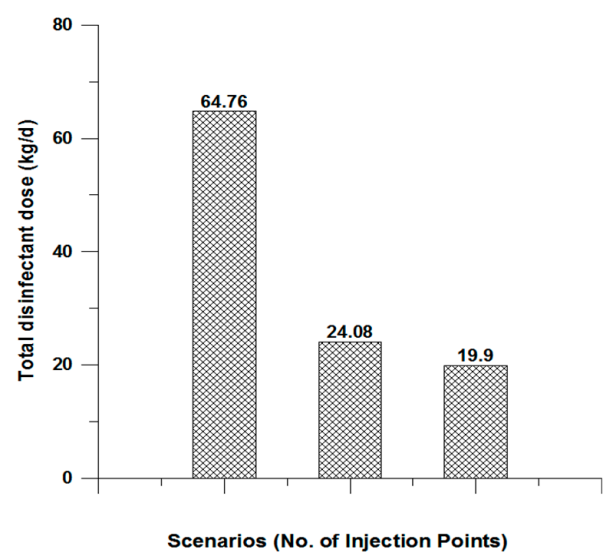

Figure 4. Changes in optimal rechlorination injection amount for 2, 3, and 4 points, using harmony search (Yoo et al. [6]).

Tables 4 and 5 provide the results of operating an optimal model under normal and abnormal conditions when needing to install 2,3, or 4 rechlorination injection facilities in the system. These are the results for the expected residual chlorine concentrations at break points when applied to the result of the optimal injection points and concentrations. It was confirmed that the optimization results of all scenarios satisfied the constraints, which is the acceptable range of residual chlorine concentration 
proposed. It is notable that the total rechlorination injection amount indicated as the result of the DDA was relatively greater than that of the PDA. In terms of the proportion, it was between $11.2 \%$ and $41.8 \%$ under normal conditions and $9.8 \%$ and $25.5 \%$ under abnormal conditions. This occurs because of the decrease in the water supply and pressure head shown in the PDA results, leading to an increase in the residual chlorine concentration, which then causes a decrease in the additional rechlorination injection amounts. The standard deviation indicates the distribution of the concentration between break points and shows smaller deviations compared to the PDA result. This suggests that increases in the deviation between break points in the hydraulic analysis, caused by the DDA result, assuming an amount of supply for all demand, affect the water quality analysis.

Table 4. Water-quality results of DDA and PDA under normal conditions.

\begin{tabular}{|c|c|c|c|}
\hline No. Injection Points & Item & DDA & PDA \\
\hline \multirow{5}{*}{2} & $\begin{array}{l}\text { Total injection amount }(\mathrm{kg} / \mathrm{d}) \\
\quad(\text { PDA/DDA } \times 100, \%)\end{array}$ & 67.96 & $7.61(11.2)$ \\
\hline & Min. (mg/L) & 0.40 & 0.56 \\
\hline & Max. (mg/L) & 3.99 & 1.58 \\
\hline & Avg. (mg/L) & 2.09 & 0.81 \\
\hline & Standard deviation & 1.06 & 0.18 \\
\hline \multirow{5}{*}{3} & Total injection amount $(\mathrm{kg} / \mathrm{d})$ & 24.53 & $10.25(41.8)$ \\
\hline & Min. (mg/L) & 0.45 & 0.48 \\
\hline & Max. (mg/L) & 3.90 & 1.35 \\
\hline & Avg. (mg/L) & 1.20 & 0.82 \\
\hline & Standard deviation & 0.81 & 0.23 \\
\hline \multirow{5}{*}{4} & Total injection amount $(\mathrm{kg} / \mathrm{d})$ & 23.92 & $8.68(36.3)$ \\
\hline & Min. (mg/L) & 0.41 & 0.42 \\
\hline & Max. (mg/L) & 3.53 & 1.80 \\
\hline & Avg. (mg/L) & 1.08 & 0.81 \\
\hline & Standard deviation & 0.64 & 0.39 \\
\hline
\end{tabular}

Table 5. Water-quality results of DDA and PDA under abnormal condition.

\begin{tabular}{|c|c|c|c|}
\hline No. Injection Points & Item & DDA & PDA \\
\hline \multirow{5}{*}{2} & $\begin{array}{l}\text { Total injection amount }(\mathrm{kg} / \mathrm{d}) \\
(\text { PDA/DDA } \times 100, \%)\end{array}$ & 66.71 & $6.53(9.8)$ \\
\hline & Min. $(\mathrm{mg} / \mathrm{L})$ & 0.41 & 0.43 \\
\hline & Max. (mg/L) & 3.90 & 1.56 \\
\hline & Avg. $(\mathrm{mg} / \mathrm{L})$ & 2.05 & 0.79 \\
\hline & Standard deviation & 1.10 & 0.22 \\
\hline \multirow{5}{*}{3} & Total injection amount $(\mathrm{kg} / \mathrm{d})$ & 19.19 & $4.89(25.5)$ \\
\hline & Min. $(\mathrm{mg} / \mathrm{L})$ & 0.41 & 0.41 \\
\hline & Max. (mg/L) & 2.23 & 2.17 \\
\hline & Avg. $(\mathrm{mg} / \mathrm{L})$ & 0.89 & 0.73 \\
\hline & Standard deviation & 0.40 & 0.37 \\
\hline \multirow{5}{*}{4} & Total injection amount $(\mathrm{kg} / \mathrm{d})$ & 14.83 & $3.38(22.8)$ \\
\hline & Min. $(m g / L)$ & 0.44 & 0.40 \\
\hline & Max. (mg/L) & 3.86 & 3.17 \\
\hline & Avg. $(\mathrm{mg} / \mathrm{L})$ & 1.00 & 0.77 \\
\hline & Standard deviation & 0.76 & 0.74 \\
\hline
\end{tabular}


Additionally, decreases in the supply are more evident under abnormal conditions, which causes additional decreases in the water pressure head than under normal conditions, leading to lower rechlorination injection amounts needed to satisfy the acceptable range of the residual chlorine concentration. This result can help intuitively understand the changes in the injection amount under various abnormal conditions. For instance, one can assume that the available amount of supply is infinite or sufficient and that there is a change in the system status, such as pipe damage or increases in demand. In this case, despite the same abnormal conditions, the demand in the system or leakage amount is expected to increase, contrary to the decrease in the amount of water source assumed in the scenario. Thus, there can be additional decreases in the residual chlorination concentration. Certainly, other external factors (e.g., system operation and distinct characteristics) can also affect the results. However, if hydraulic and water-quality analysis results can be obtained while reflecting the characteristics of the system based the method proposed in this study, it can help with decision-making to address increases in rechlorination injection amounts and water quality issues.

Figures 5 and 6 provide network diagrams with locations of the optimal rechlorination injection points for normal and abnormal conditions. The injection points were selected focusing on injection points and end points of the system in the DDA result, whereas the center of the system or the points where flow rates split were selected in the PDA result. This result suggests that, because the deviations between break points for the residual chlorine concentration were relatively high in the DDA, it was necessary to select the injection points or end points as rechlorination points, because they had the minimum concentrations within the acceptable range of the concentration. However, in the case of PDA, the deviations were relatively low, and the amount of the additional chlorine injection was also low, producing an insignificant change. However, the flow-rate split, triggering a change of the uniform concentration as determined by the optimal point.

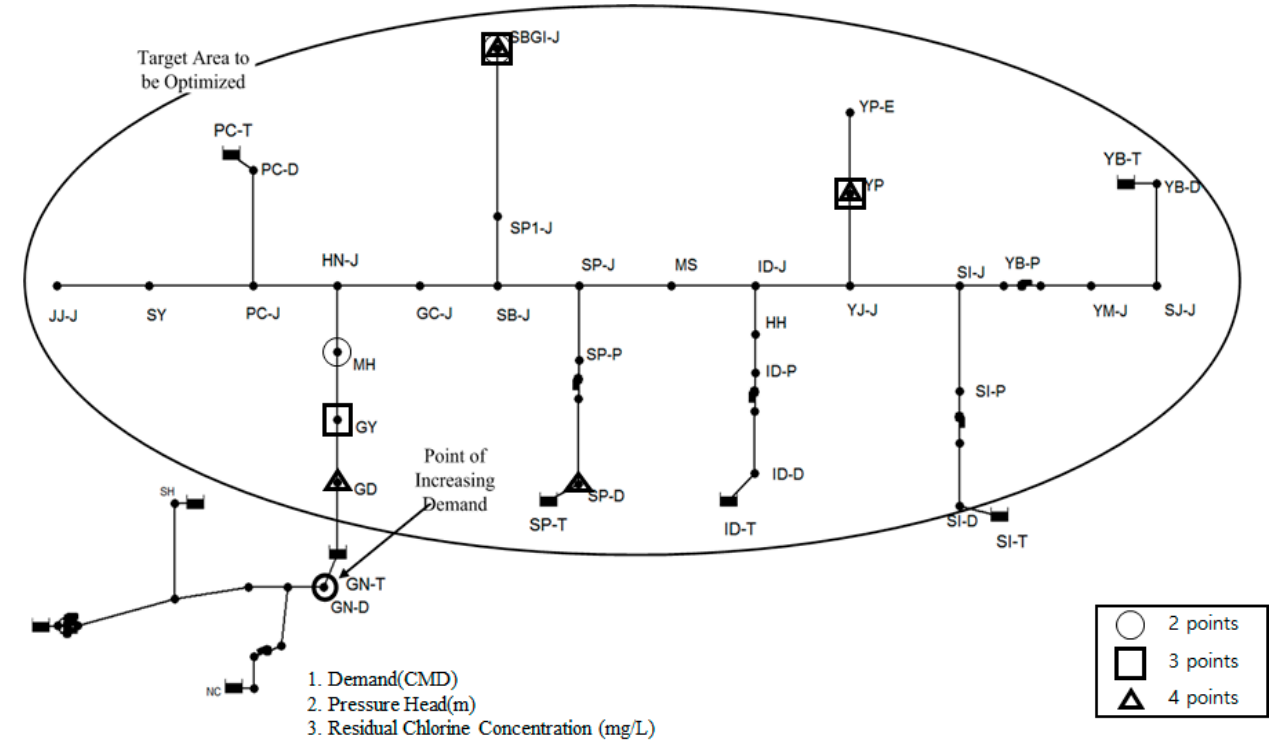

(a) DDA optimal points

Figure 5. Cont. 


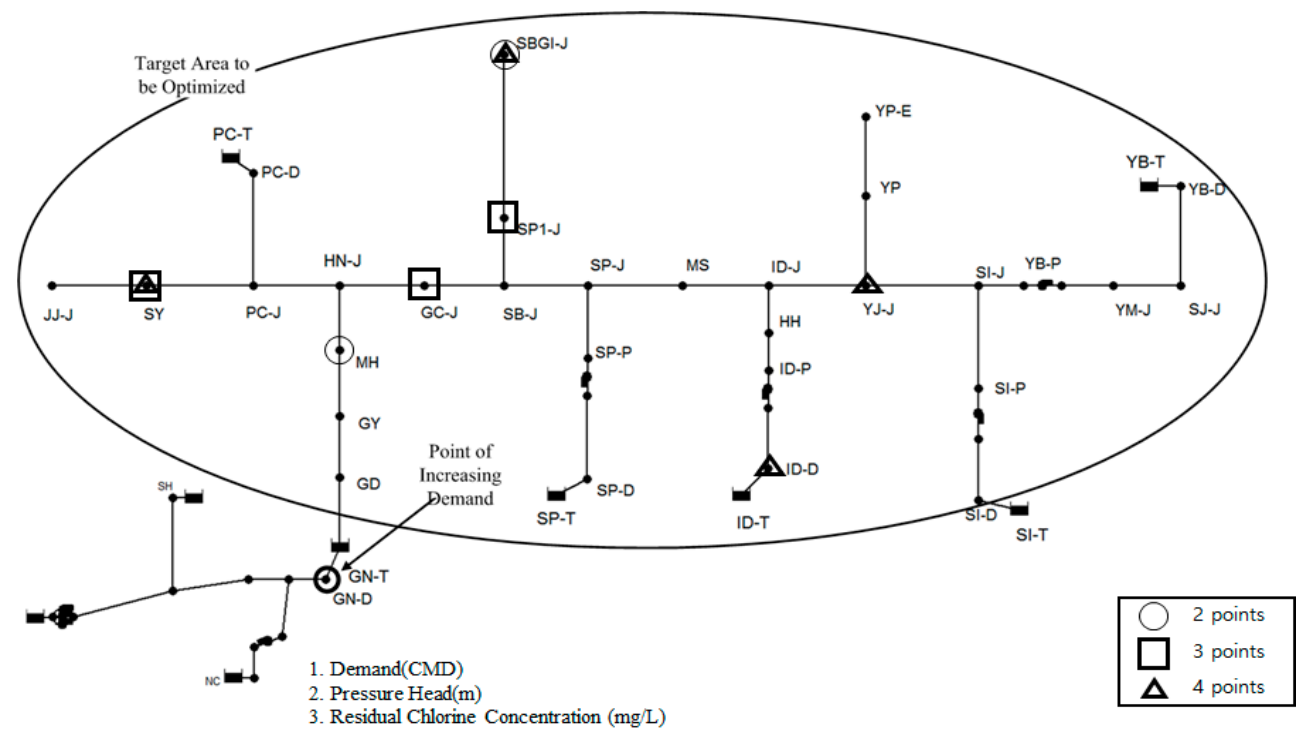

(b) PDA optimal points

Figure 5. Optimal points under normal conditions.

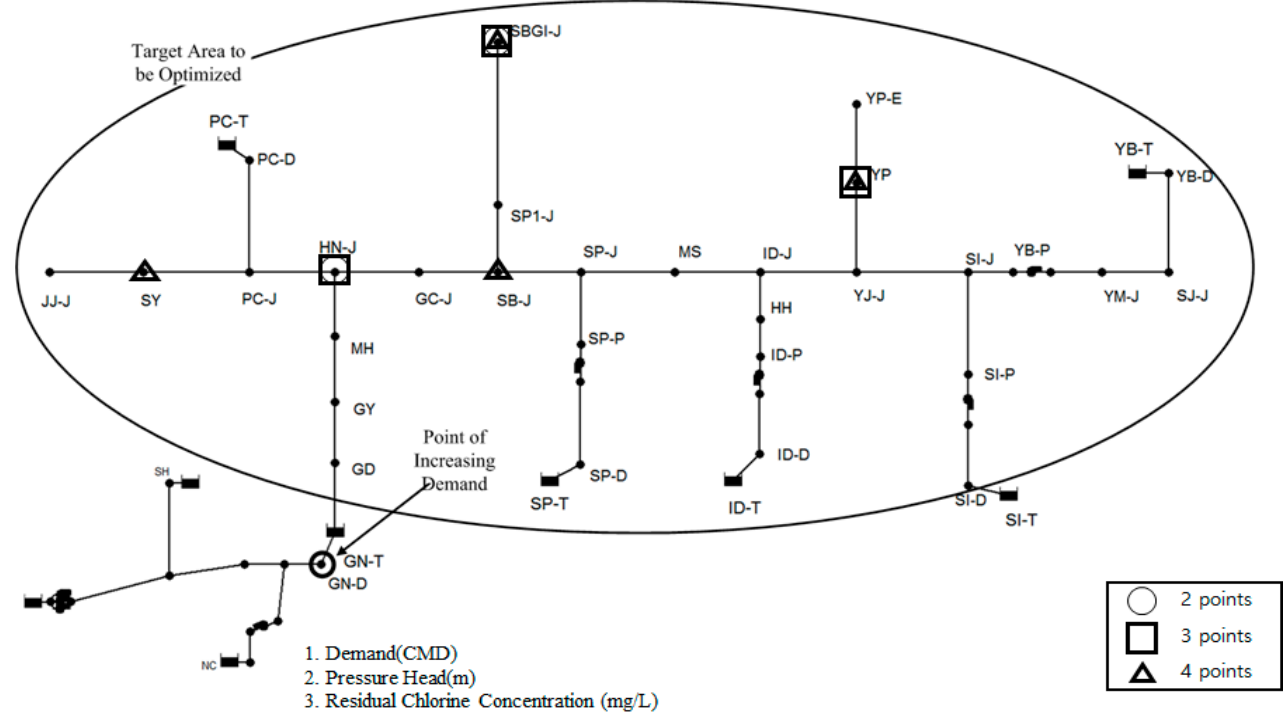

(a) DDA optimal points

Figure 6. Cont. 


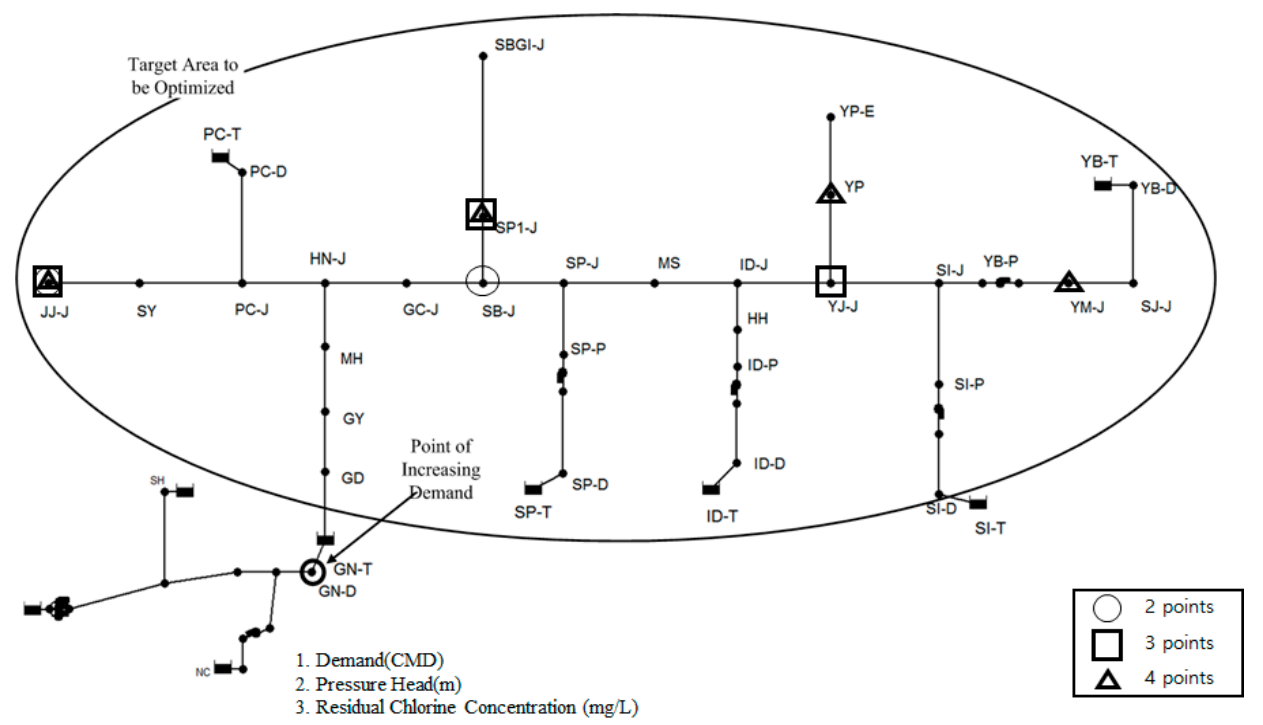

(b) PDA optimal points

Figure 6. Optimal points in abnormal conditions.

Tables 6 and 7 provide the residual chlorine concentration levels, shown in each break point when rechlorination facilities are installed at two locations. As suggested, the deviation in the residual chlorine concentration in the DDA result is greater than that of the PDA result. However, it satisfies all constraints for an acceptable residual chlorine concentration for all analyses.

Table 6. Two injection-point results under normal conditions.

\begin{tabular}{|c|c|c|c|c|c|c|}
\hline \multicolumn{4}{|c|}{ EPANET2 DDA } & \multicolumn{3}{|c|}{ K-NRiskQ PDA } \\
\hline Junction ID & $\begin{array}{c}\text { Injection } \\
\text { Rate }(\mathrm{mg} / \mathrm{L})\end{array}$ & $\begin{array}{c}\text { Injection } \\
\text { Mass (kg/d) }\end{array}$ & $\begin{array}{c}\text { Residual } \\
\text { Chlorine }(\mathrm{mg} / \mathrm{L})\end{array}$ & $\begin{array}{c}\text { Injection } \\
\text { Rate (mg/L) }\end{array}$ & $\begin{array}{c}\text { Injection } \\
\text { Mass (kg/d) }\end{array}$ & $\begin{array}{c}\text { Residual } \\
\text { Chlorine (mg/L) }\end{array}$ \\
\hline GN-D & & 0 & 0.45 & & 0 & 0.73 \\
\hline GD & & 0 & 0.58 & & 0 & 0.58 \\
\hline GY & & 0 & 0.54 & & 0 & 0.56 \\
\hline $\mathrm{MH}$ & 3.47 & 67.64 & 3.99 & 0.41 & 7.42 & 0.96 \\
\hline HN-J & & 0 & 3.83 & & 0 & 0.92 \\
\hline PC-J & & 0 & 3.65 & & 0 & 0.92 \\
\hline SY & & 0 & 3.46 & & 0 & 0.90 \\
\hline JJ-J & & 0 & 1.69 & & 0 & 0.71 \\
\hline PC-D & & 0 & 3.44 & & 0 & 0.89 \\
\hline GC-J & & 0 & 3.65 & & 0 & 0.89 \\
\hline SB-J & & 0 & 3.19 & & 0 & 0.89 \\
\hline SP-J & & 0 & 2.88 & & 0 & 0.89 \\
\hline MS & & 0 & 2.75 & & 0 & 0.84 \\
\hline ID-J & & 0 & 2.63 & & 0 & 0.84 \\
\hline YJ-J & & 0 & 2.26 & & 0 & 0.76 \\
\hline SI-J & & 0 & 1.92 & & 0 & 0.74 \\
\hline YB-P & & 0 & 1.70 & & 0 & 0.71 \\
\hline YM-J & & 0 & 1.32 & & 0 & 0.70 \\
\hline
\end{tabular}


Table 6. Cont.

\begin{tabular}{|c|c|c|c|c|c|c|}
\hline \multicolumn{4}{|c|}{ EPANET2 DDA } & \multicolumn{3}{|c|}{ K-NRiskQ PDA } \\
\hline Junction ID & $\begin{array}{c}\text { Injection } \\
\text { Rate (mg/L) }\end{array}$ & $\begin{array}{c}\text { Injection } \\
\text { Mass (kg/d) }\end{array}$ & $\begin{array}{c}\text { Residual } \\
\text { Chlorine (mg/L) }\end{array}$ & $\begin{array}{c}\text { Injection } \\
\text { Rate (mg/L) }\end{array}$ & $\begin{array}{c}\text { Injection } \\
\text { Mass (kg/d) }\end{array}$ & $\begin{array}{c}\text { Residual } \\
\text { Chlorine }(\mathrm{mg} / \mathrm{L})\end{array}$ \\
\hline SJ-J & & 0 & 1.18 & & 0 & 0.67 \\
\hline YB-D & & 0 & 1.07 & & 0 & 0.68 \\
\hline SP1-J & & 0 & 1.96 & & 0 & 0.87 \\
\hline SBGI-J & 2.70 & 0.31 & 2.80 & 1.58 & 0.18 & 1.58 \\
\hline SP-P & & 0 & 2.35 & & 0 & 0.87 \\
\hline SP-D & & 0 & 1.91 & & 0 & 0.84 \\
\hline ID-P & & 0 & 1.72 & & 0 & 0.69 \\
\hline ID-D & & 0 & 1.59 & & 0 & 0.77 \\
\hline $\mathrm{HH}$ & & 0 & 1.98 & & 0 & 0.74 \\
\hline $\mathrm{YP}$ & & 0 & 0.77 & & 0 & 0.75 \\
\hline YP-E & & 0 & 0.40 & & 0 & 0.69 \\
\hline SI-P & & 0 & 1.69 & & 0 & 0.75 \\
\hline SI-D & & 0 & 1.57 & & 0 & 0.70 \\
\hline
\end{tabular}

Table 7. Two injection-point results under abnormal conditions.

\begin{tabular}{|c|c|c|c|c|c|c|}
\hline \multicolumn{4}{|c|}{ EPANET2 DDA } & \multicolumn{3}{|c|}{ K-NRiskQ PDA } \\
\hline Junction ID & $\begin{array}{c}\text { Injection } \\
\text { Rate }(\mathrm{mg} / \mathrm{L})\end{array}$ & $\begin{array}{l}\text { Injection } \\
\text { Mass (kg/d) }\end{array}$ & $\begin{array}{c}\text { Residual } \\
\text { Chlorine }(\mathrm{mg} / \mathrm{L})\end{array}$ & $\begin{array}{c}\text { Injection } \\
\text { Rate }(m g / L)\end{array}$ & $\begin{array}{c}\text { Injection } \\
\text { Mass (kg/d) }\end{array}$ & $\begin{array}{c}\text { Residual } \\
\text { Chlorine (mg/L) }\end{array}$ \\
\hline GN-D & & 0 & 0.45 & & 0 & 0.73 \\
\hline GD & & 0 & 0.58 & & 0 & 0.58 \\
\hline GY & & 0 & 0.54 & & 0 & 0.55 \\
\hline $\mathrm{MH}$ & & 0 & 0.52 & & 0 & 0.55 \\
\hline HN-J & 3.40 & 66.28 & 3.90 & & 0 & 0.53 \\
\hline PC-J & & 0 & 3.72 & & 0 & 0.52 \\
\hline SY & & 0 & 3.53 & & 0 & 0.50 \\
\hline JJ-J & & 0 & 1.72 & 1.18 & 1.18 & 1.56 \\
\hline PC-D & & 0 & 3.50 & & 0 & 0.49 \\
\hline GC-J & & 0 & 3.72 & & 0 & 0.51 \\
\hline SB-J & & 0 & 3.25 & 0.50 & 5.35 & 0.96 \\
\hline SP-J & & 0 & 2.94 & & 0 & 0.98 \\
\hline MS & & 0 & 2.80 & & 0 & 0.93 \\
\hline ID-J & & 0 & 2.68 & & 0 & 0.90 \\
\hline YJ-J & & 0 & 2.30 & & 0 & 0.91 \\
\hline SI-J & & 0 & 1.95 & & 0 & 0.93 \\
\hline YB-P & & 0 & 1.74 & & 0 & 0.87 \\
\hline YM-J & & 0 & 1.35 & & 0 & 0.85 \\
\hline SJ-J & & 0 & 1.21 & & 0 & 0.86 \\
\hline YB-D & & 0 & 1.09 & & 0 & 0.81 \\
\hline SP1-J & & 0 & 2.00 & & 0 & 0.93 \\
\hline SBGI-J & 3.69 & 0.43 & 3.80 & & 0 & 0.43 \\
\hline SP-P & & 0 & 2.39 & & 0 & 0.97 \\
\hline
\end{tabular}


Table 7. Cont.

\begin{tabular}{ccccccc}
\hline & \multicolumn{2}{c}{ EPANET2 DDA } & \multicolumn{3}{c}{ K-NRiskQ PDA } \\
\hline Junction ID & $\begin{array}{c}\text { Injection } \\
\text { Rate (mg/L) }\end{array}$ & $\begin{array}{c}\text { Injection } \\
\text { Mass (kg/d) }\end{array}$ & $\begin{array}{c}\text { Residual } \\
\text { Chlorine (mg/L) }\end{array}$ & $\begin{array}{c}\text { Injection } \\
\text { Rate (mg/L) }\end{array}$ & $\begin{array}{c}\text { Injection } \\
\text { Mass (kg/d) }\end{array}$ & $\begin{array}{c}\text { Residual } \\
\text { Chlorine (mg/L) }\end{array}$ \\
\hline SP-D & 0 & 1.94 & 0 & 0.90 \\
\hline ID-P & 0 & 1.75 & 0 & 0.83 \\
\hline ID-D & 0 & 1.62 & 0 & 0.86 \\
\hline HH & 0 & 2.02 & 0 & 0.87 \\
\hline YP & 0 & 0.78 & 0 & 0.84 \\
\hline YP-E & 0 & 0.41 & 0 & 0.74 \\
\hline SI-P & 0 & 1.72 & 0 & 0.81 \\
\hline SI-D & 0 & 1.60 & 0 & 0.86 \\
\hline
\end{tabular}

\section{Conclusions}

A methodology was proposed for determining the location of rechlorination facilities and dosages, using an in-depth comparative analysis, performed on the results of PDA and DDA. A simple greedy algorithm was used in the optimal solution calculation model, and the model was operated under four different scenarios, with the settings of normal and abnormal conditions. The model was operated for 2, 3, and 4 chlorine injection points, and the results showed that all break points satisfied the minimum and maximum residual chlorine concentration standard. Whereas the greedy algorithm did not provide a result superior to the complex metaheuristic optimization method, it was close enough and was confirmed to be an adequate model to serve the purpose of this study, which entailed the comparison of hydraulic analysis results. In terms of determining rechlorination injection points through DDA and PDA, we confirmed that the DDA model showed significant spatial deviations in the presence of water pressure head decreases, leading to an overestimation of injection amounts. However, the proposed model, which involved PDA, showed that it had less rechlorination injection amounts determined to meet the acceptable range, compared to the DDA model. Because the PDA model is applied as a numerically validated theory, it appears to offer a more rational hydraulic and water-quality analysis based on rechlorination injection amounts. Furthermore, the optimization of rechlorination injection was performed with a scenario of abnormal conditions. Thus, it was confirmed that an increase or decrease in the amount of supply of the overall system, caused by abnormal conditions, affected the amount of the rechlorination injection. Thus, the results could vary depending on whether the supply-flow rate of the system decreased or increased. When the model proposed in this study was used, more realistic hydraulic and water quality analysis results were obtained, and the tendency of the water-quality results under normal and abnormal conditions was confirmed. This model can be used as a hydraulic analysis-based decision-making tool to supply water of a stable quality.

In the future, an extended period simulation should be conducted to ensure an adequate level of residual chlorine throughout the entire period, rather than a single-period simulation based on average demand. Additionally, further studies will need to be applied to more diverse scales and complex network systems (branched and looped type systems) and their results should be analyzed. Furthermore, changes in water-quality analysis results should be examined in more variety, and there should be studies on the development of indices to be used in decision-making. Furthermore, the water age and pressure head can be used as an additional design and operational factor for the overall evaluation of WSN.

Author Contributions: S.M.L. and J.H.K. conceived and designed the original idea of proposed method; D.G.Y. and S.M.L. carried out survey of previous studies; S.M.L., D.G.Y., and H.M.L. analyzed the data; S.M.L. and D.G.Y. wrote the paper.

Funding: This work was supported by a grant from the National Research Foundation (NRF) of Korea, funded by the Korean government (MSIP) (No. 2016R1A2A1A05005306). 
Conflicts of Interest: The authors declare no conflict of interest.

\section{References}

1. K-water. Final Reports of Smart Water City Projects; K-water: Daejeon, Korea, 2016.

2. Boccelli, D.L.; Tryby, M.E.; Uber, J.G.; Rossman, L.A.; Zierolf, M.L.; Polycarpou, M.M. Optimal scheduling of booster disinfection in water distribution systems. J. Water Resour. Plan. Manag. 1998, 124, 99-111. [CrossRef]

3. Munavalli, G.R.; Kumar, M.M. Optimal scheduling of multiple chlorine sources in water distribution systems. J. Water Resour. Plan. Manag. 2003, 129, 493-504. [CrossRef]

4. Tryby, M.E.; Boccelli, D.L.; Uber, J.G.; Rossman, L.A. Facility location model for booster disinfection of water supply networks. J. Water Resour. Plan. Manag. 2002, 128, 322-333. [CrossRef]

5. Propato, M.; Uber, J.G. Linear least-squares formulation for operation of booster disinfection systems. J. Water Resour. Plan. Manag. 2003, 130, 53-62. [CrossRef]

6. Yoo, D.G.; Lee, S.M.; Lee, H.M.; Choi, Y.H.; Kim, J.H. Optimizing Re-Chlorination Injection Points for Water Supply Networks Using Harmony Search Algorithm. Water 2018, 10, 547. [CrossRef]

7. Prasad, T.D.; Walters, G.A.; Savic, D.A. Booster disinfection of water supply networks: Multiobjective approach. J. Water Resour. Plan. Manag. 2004, 130, 367-376. [CrossRef]

8. Ostfeld, A.; Salomons, E. Conjunctive optimal scheduling of pumping and booster chlorine injections in water distribution systems. Eng. Optim. 2006, 38, 337-352. [CrossRef]

9. Islam, N.; Sadiq, R.; Rodriguez, M.J. Optimizing booster chlorination in water distribution networks: A water quality index approach. Environ. Monit. Assess. 2013, 185, 8035-8050. [CrossRef]

10. Choi, T.; Lee, D.; Bae, C.; Moon, J. Analysing the Effect of Residual Chlorine Equalization for Water Quality Improvement in Water Distribution System. J. Korean Soc. Water Wastewater 2016, 30, 587-596. [CrossRef]

11. Rossman, L. EPANET User's Manual; United States Environmental Protection Agency (EPA): Washington, DC, USA, 2000.

12. Giustolisi, O.; Kapelan, Z.; Savic, D.A. Extended period simulation analysis considering valve shutdowns. J. Water Resour. Plan. Manag. 2008, 134, 527-537. [CrossRef]

13. Giustolisi, O.; Savic, D.A.; Kapelan, Z. Pressure-driven demand and leakage simulation for water distribution networks. J. Hydraul. Eng. 2008, 134, 626-635. [CrossRef]

14. Wu, Y.W.; Wang, R.H.; Walski, T.M.; Yang, S.Y.; Bowdler, D.; Baggett, C.C. Extended global-gradient algorithm for pressure-dependent water distribution analysis. J. Water Resour. Plan. Manag. 2009, 135, 13-22. [CrossRef]

15. Lee, H.M.; Yoo, D.G.; Kang, D.; Jun, H.; Kim, J.H. Uncertainty quantification of pressure-driven analysis for water distribution network modeling. Water Sci. Technol. Water Supply 2016, 16, 599-610. [CrossRef]

16. Yoo, D.G.; Chang, D.E.; Song, Y.H.; Lee, J.H. Optimal Placement of Pressure Gauges for Water Distribution Networks Using Entropy Theory Based on Pressure Dependent Hydraulic Simulation. Entropy 2018, $20,576$. [CrossRef]

17. Seyoum, A.G.; Tanyimboh, T. Pressure dependent network water quality modelling. Proc. ICE-Water Manag. 2014, 167, 342-355. [CrossRef]

18. Seyoum, A.G.; Tanyimboh, T.; Siew, C. Comparison of demand driven and pressure dependent hydraulic approaches for modelling water quality in distribution networks. In Proceedings of the 11th International Conference on Computing and Control for the Water Industry, Exeter, UK, 5-7 September 2011.

19. Seyoum, A.G.; Tanyimboh, T.T.; Siew, C. Assessment of water quality modelling capabilities of EPANET multiple species and pressure-dependent extension models. Water Sci. Technol. Water Supply 2013, 13, 1161-1166. [CrossRef]

20. Seyoum, A.G.; Tanyimboh, T.T. Integration of hydraulic and water quality modelling in distribution networks: EPANET-PMX. Water Resour. Manag. 2017, 31, 4485-4503. [CrossRef]

21. WaterGEMs User's Manual. Available online: https://www.bentley.com/en/products/product-line/hydraulicsand-hydrology-software/watergems (accessed on 4 April 2019).

22. EPANET3. Available online: https://github.com/OpenWaterAnalytics/epanet-dev (accessed on 4 April 2019).

23. Carrico, B.; Singer, P.C. Impact of booster chlorination on chlorine decay and THM production: Simulated analysis. J. Environ. Eng. 2009, 135, 928-935. [CrossRef]

24. Courtis, B.J.; West, J.R.; Bridgeman, J. Chlorine demand-based predictive modeling of THM formation in water distribution networks. Urban Water J. 2009, 6, 407-415. [CrossRef] 
25. Powell, J.C.; Hallam, N.B.; West, J.R.; Forster, C.F.; Simms, J. Factors which control bulk chlorine decay rates. Water Res. 2000, 34, 117-126. [CrossRef]

26. Tamminen, S.; Ramos, H.; Covas, D. Water supply system performance for different pipe materials Part I: Water quality analysis. Water Resour. Manag. 2008, 22, 1579-1607. [CrossRef]

27. K-water. K-NRisk User's Manual; K-water: Daejeon, Korea, 2017.

28. K-water. K-NRiskQ User's Manual; K-water: Daejeon, Korea, 2018.

29. Korea Water Works Association (KWWA). Standards for Water Supply Facilities; Korea Water Works Association (KWWA): Seoul, Korea, 2010.

30. Wagner, J.M.; Shamir, U.; Marks, D.H. Water distribution reliability: Simulation methods. J. Water Resour. Plan. Manag. 1988, 114, 276-294. [CrossRef]

31. Al-Jasser, A.O. Chlorine decay in drinking-water transmission and distribution systems: Pipe service age effect. Water Res. 2007, 41, 387-396. [CrossRef]

32. Hallam, N.B.; West, J.R.; Forster, C.F.; Powell, J.C.; Spencer, I. The decay of chlorine associated with the pipe wall in water distribution systems. Water Res. 2002, 36, 3479-3488. [CrossRef]

(C) 2019 by the authors. Licensee MDPI, Basel, Switzerland. This article is an open access article distributed under the terms and conditions of the Creative Commons Attribution (CC BY) license (http://creativecommons.org/licenses/by/4.0/). 